\title{
THE CONNOTATIVE MEANING OF CORONAVIRUS IMPACT EXPRESSIONS IN TEMPO ENGLISH MAGAZINE
}

\author{
Usti Maula $^{1}$ and Rahma Ilyas ${ }^{2}$ \\ MAN 1 Majalengka ${ }^{1}$, Majalengka, maulausti@gmail.com \\ Universitas Majalengka², Majalengka,rahmailyas@unma.ac.id
}

\begin{abstract}
This research focuses on analyzing coronavirus impact expressions in Tempo English magazine by using theory of connotative meaning from Leech as the grand theory and from Hook as the supporting theory. The focus is on two kinds of connotative meaning, namely, positive and negative connotative meaning. The objectivities of this research are to find out and to explain the use of negative and connotative meaning. The research is qualitative by which helps the researcher to describe the data being studied. In analyzing qualitative data, there are various kinds of methods, including qualitative content analysis. The use of a qualitative content analysis in this research is to know, to describe, and to analyze the use of connotative meaning applied in Tempo English magazine, April 14, 2020 edition. The result of this research is that Tempo English magazine uses many connotative meaning of coronavirus impact expressions. There are 15 expressions as negative connotative meaning and 12 expressions as positive connotative meaning. The findings indicates that the use negative connotative meaning of coronavirus impact expressions in Tempo English magazine are associated with threats in economy sector and associated with inappropriate government policies in an effort to prevent the spread of covid-19 as well as the impact of pandemic in many sectors. Besides, the use positive connotative meaning of coronavirus impact expressions in Tempo English magazine are associated with solutions to avoid spread of Covid-19 as well as solutions to avoid the impact of pandemic, and associated with the government's responsibility and seriousness in dealing with preventing the spread of coronavirus as well as in dealing with the impact of coronavirus.
\end{abstract}

Keywords: semantics; connotative meaning; coronavirus impact

\section{INTRODUCTION}

Reading news is one of the daily activities for some people, especially since being home because of coronavirus. Generally, the purpose of reading news is to find out information about what happened in the world recently. Print media, broadcast, and internet are the three main categories in news media. Talking about information in the news, the information will be conveyed clearly if the public can understand the meaning of the information that contains in the news. Talking about meaning can be found in one of the branches of linguistics. Linguistics is scientific study of language. Linguistics may be defined as the scientific study of language if the research controlled and empirical verifiable observed with some general theory of language structure as the reference (Lyons, 1995). There are four main branches in linguistics; they are phonology, morphology, syntax, and semantics (Akmajian, Demers, Farmer, \& Harnish, 2010). 
This research, the researcher decided to analyze one of the news media using semantics theory. As Akmajian et al. (2010) state above that semantics is the study of meaning in words, phrases, and sentences. Understanding meaning is important in reading process. The information in the news will not convey clearly if the readers cannot understand the meaning of the information contains in the news. Besides, since the presence of coronavirus so many new words and phrases that related to coronavirus impact expressions are popping up in the news, such as outbreak, pandemic, quarantine, self-isolating, social distancing, lockdown, and many more. These words and phrases have increased in use in articles and suddenly become part of everyday lives. It is important to understand these words and phrases because they can mean different things.

Understanding new words and phrases of coronavirus impact expressions in a conceptual sense is not enough; they also have connotative meaning that must understand by the readers. Understanding the meaning can appear from various aspects and depends on the point of view. Connotative meaning is the meaning that has communicative value of what it refers to and it has meaning that above conceptual meaning (Leech, 1981, p. 12). Woman is defined conceptually as + human, - male, + adult, but it will different meanings when contrasting it with connotative meaning. In connotative meaning, woman not only interpreted in physical characteristics (having a womb), but also about physiological and social properties (gregarious, subject to maternal instinct). Thereunto, connotative meaning also depends on point of view adopted by an individual or a group of people. For example, woman has been burdened with such attributes frail, prone to tears, and emotional. Thus, the connotative meaning is relatively unstable; it depends on culture, historical period, and the experience of the individual.

Besides, according to other expert, states that meaning is more than denotation. Language provides a means for expressing a wide variety of attitudes. People can express their opinions. This aspect is called connotation. It refers to personal aspects and emotional that the word arouses (Kreidler, 1998, p. 44). Kreidler associate connotative with value and feeling. Some of the connotative meanings considered positive value and some of the other connotative meanings considered negative value or perhaps neutral. In summary, connotative meaning includes the attitude of a society and the individuals. Furthermore, Finch (2003, p. 135) adds that when talking about connotative meaning is talking about the kinds of values and attitudes invoked by a word apart from its core meaning. For example, the word man, most people agree that man is a human, male, and adult. Nevertheless, in connotative the word man is more than that. People need to know what extra qualities that man have according to the speaker. It is probably referred to strength, bravery, and so forth. Besides, for some societies, in the past woman considered emotional, sentimental, weak, prone to tears, and so on. Thus, man and woman conceptually as human and adult, but they have different value in terms of connotation. Man refers to positive connotative meaning (strength and bravery) while woman refers to negative connotative meaning (emotional, sentimental, weak, and prone to tears).

From the explanation above shows that the connotative meaning is divided into three types, they are positive, negative, and neutral value or feeling. As Hook in Widarso (2000, p. 71) states that in connotative meaning there are positive and negative connotative. Between positive connotative meaning and negative connotative meaning is neutral words, some of which are jargon. Jargon is usually 
associated with a field or used by professional groups. Hook also called positive connotative meaning as purr words while negative connotative meaning as snarl words. According to Oxford dictionary, purr is when a cat purrs, it makes a low continuous sound in the throat especially when it is happy or comfortable. Purr also refers to speak in a low and gentle voice, for example to show happiness or satisfy (Hornby, 2010, p. 1193). Besides, Snarl is when somebody or something (such as dogs, etc.) shows the teeth and makes a deep angry noise in the throat or speaks in an angry or bad-tempered way (Hornby, 2010, p. 1408). Moreover, according to Hayakawa in Leech (1981, p. 44), states that snarl words are words in unfavorable connotation in order to give forceful expressions to his own hostility. Terms for extreme political views, such as communist or fascist. The opposite category of purr words has already been illustrated in the word democratic; other potential political purr words are freedom, human rights, patriotic, fatherland, and equality. In summary, snarl words are terms that make people react negatively, while purr words are terms that make people feel good about the subject being addressed.

Most of researchers who are interested to analyze connotative meaning usually choose song lyrics as the object of research, but Finch (2003, p. 136) states that advertising and journalism text also contains connotative meaning. Connotative meaning is consistently exploited by writers who want to engage the emotions, stimulate the imaginations, or feed the prejudices where it can be found in advertising and journalism text. Thus, the researcher decided to analyze connotative meaning in article because the article also has connotative meaning. The researcher has been chosen article of Tempo English magazine as the object of research. Tempo English refers to Tempo magazine that published in English. Tempo is weekly magazine that covers news and politics. Tempo is an independent institution, a truly non-government organization. The first edition was published in March 1971. In 1994, the government of Indonesia banned the publishing of Tempo magazine and published it again in 1997 (Steele, 2005). Tempo magazine is published in two languages, which are Bahasa Indonesia and English. Along with the time, for now, it is easy to find Tempo magazine. The customers can find it on their official website, magz.tempo.co. Additionally, it can also be found in applications such as Gramedia Digital.

In this research, the researcher focused on Tempo English April 14, 2020 edition as the object of research. This edition, the magazine contains a lot of expressions that discusses about the impact of coronavirus. Besides, COVID-19 does not only affect public health but also affects other sectors such as economic and social. The coronavirus impact expressions that contain in Tempo English also has a connotative meaning that must understand by the readers. Thus, the researcher is interested in analyzing positive and negative connotative meaning in the article. The own entitled "The Connotative Meaning of Coronavirus Impact Expressions in Tempo English Magazine".

\section{LITERATURE REVIEW}

There are several types of meaning. Geoffrey Leech (1981, p. 9) in his book with title Semantics: the study of meaning, he breaks down meaning into seven types, they are conceptual meaning, connotative meaning, social meaning, affective meaning, reflected meaning, collocative meaning, and thematic meaning. The aim 
of dividing the seven types of meaning is to show how methods of study appropriate to one type may not be appropriate to another.

Generosity maxim Conceptual meaning is also known as denotative meaning. Understanding denotative meaning can be found in dictionary. The aim of contrastive features in denotative meaning is for given interpretation of a sentence and show exactly what we need to know if we want to distinguish that meaning from other possible sentence meaning in the language (Leech, 1981, p. 11). Denotative meaning also provide for any given interpretation of a sentence. Therefore, denotative meaning is essential part in a language. Denotative meaning assumed to be the central factor in linguistics communication (Leech, 1981, p. 9). Communication will not keep going if the speaker and the listener cannot understand the denotative meaning each other. It was shown to the basis of language, so before compare with other types of meaning, the most important is to understand denotative meaning at first.

Associative meaning is different with conceptual meaning. The different between the conceptual meaning and the associative meaning is based on whether or not the meaning of a word is related to the meaning of another word (Chaer, 2009 , p. 72). The conceptual meaning is the meaning accordance with the concept, the same meaning as the reference, the meaning that is free from any association or relationship. Meanwhile, the associative meaning is the meaning that has relationship between the word and conditions outside of language. In other word, associative meaning is the symbol used by a language society to express another concept. Leach divided associative meaning into five types; they are included connotative meaning, social meaning, affective meaning, reflected meaning, and collocative meaning.

Leech (1981, p. 12) gives definition that connotative meaning is the meaning that has a communicative value of what it refers to and it has the meaning that above denotative meaning. Value is a collective conception of whether it is considered good, bad, or neutral. Connotative meaning is wider than denotative meaning. The difference in denotative meaning and connotative meaning will appear when contrasted with one another. For example, woman is conceptually defined as + human, - male, + adult, but it will have a different meaning if it is contrasted with connotative meaning. In connotative meaning, woman not only interpreted in physical characteristics (such as having a womb), but also about physiological and social properties (such as gregarious, subject to maternal instinct).

There are three important points in understanding the connotative meaning. Talking about connotation is talking about the real world. The connotations are relatively unstable. The connotative meaning is indeterminate and open-ended (Leech, 1981, p. 13). The first point, the connotative is about experience of one that associates with an expression when one uses or hears it. The second point is that denotative meaning is stable while connotative meanings are relatively unstable, it considers several things, whether the culture, the historical period, the surrounding environment, or the experience of the individual. For a society the connotative meaning is considered a positive value but probably for some of the other societies the connotative meaning is considered a negative value or perhaps neutral. The last point, connotative meaning is open-ended while denotative meaning is not. In the same way as our knowledge and beliefs about 
the universe are open-ended. Therefore, there is no limitation in connotative meaning.

Specifically, the connotative meaning is divided into three types, they are positive, negative, and neutral value or feeling. As Hook in Widarso (1989, p. 71) states that in connotative meaning there are positive and negative connotative. Between positive connotative meaning and negative connotative meaning is neutral words, some of which are jargon. Jargon is usually associated with a field or used by professional groups. Hook also called positive connotative meaning as purr words while negative connotative meaning as snarl words. According to Hayakawa in Leech $(1981$, p. 41) states that snarl words are words in unfavorable connotation in order to give forceful expression to his own hostility. Terms for extreme political views, such as communist or fascist. The opposite category of purr words has already been illustrated in the word democratic, other potential political purr words are freedom, human rights, patriotic, fatherland, and equality. In summary, snarl words are terms that make people react negatively, while purr words are terms that make people feel comfortable with the subject being addressed.

This paper focuses on the analysis of connotative meaning of language used in an online magazine. Online magazine or sometimes called electronic magazine or e-magazine refers to a magazine that published on the internet. One of the magazine that going to online is Tempo English magazine. Tempo is an Indonesian weekly magazine that covers news and politics. Tempo is an independent institution, a truly non-government organization. Tempo magazine is published in two languages, which are Bahasa Indonesia and English. The first edition was published in March 1971. However, in 1994, the government of Indonesia banned the publishing of Tempo magazine and published it again in 1997 (Steele, 2005).

Along with the time, for now, it is easy to find Tempo magazine. The customers can find it in digital form on their official website, magz.tempo.co. Additionally, it can also be found in applications such as Tempo and Gramedia Digital. Tempo is a magazine that provides political, economic news coverage, and in-depth investigations of issues occurring in Indonesia. One of the issues in Indonesia in 2020 is coronavirus. This issue available in Tempo English magazine April 14, 2020 edition.

The main topic in Tempo English magazine April 14, 2020 edition is about the coronavirus and its impact in several sectors such as the labor sector, business, economic, social movement, tourism industry, transportation services, and government policies. The total number of pages in this edition is 52 pages. It consists of 9 rubrics, namely letters, opinion, cover story, interlude, national, news capsule, economy, interview, and sidelines.

\section{METHOD}

This research is designed in a qualitative research. This method helps the researcher to describe the data being studied qualitatively. The data collected in the form of words. As Creswell states (2014, p. 32) that qualitative research is framed in terms of using words instead of numbers. Furthermore, Bogdan \& Biklen (2006, p. 5) also state that qualitative research is always descriptive that the data are in the form 
of words or pictures instead of numbers. Therefore, qualitative is obviously concerned with the data described in words rather than in numbers.

In analyzing qualitative data, there are various kinds of methods, including qualitative content analysis. Qualitative content analysis is one of the research methods used to analyze text as data. This method focuses on the characteristic of language as communication with attention to the content or textual meaning of the text (Budd, Thorp, \& Donohew, 1967). Schreier (2012) conceptualizes the qualitative content analysis as a method for analyzing data and interpreting its meaning. Further, the purpose of content analysis is to provide an interpretation of text data content through a systematic classification process of coding and identifying themes or patterns (Shannon \& Hsieh, 2005, p. 1278). Berg (2001) in Zhang \& Wildemuth (2005, p. 2197) state that qualitative content analysis is usually inductive, produces descriptions, and samples consist of purposive sampling that can inform the research question being investigated.

Based on the theoretical consideration above, it is clear that the use of a qualitative content analysis in this research is to know, to describe, and to analyze the use of connotative meaning applied in Tempo English magazine, April 14, 2020 edition. It includes positive connotative meaning and negative connotative meaning. Therefore, qualitative content analysis is appropriate to obtain the objectives of this research.

\section{FINDINGS AND DISCUSSIONS}

The research used articles from Tempo English magazine April 14, 2020 edition as the data analysis by applying connotative meaning theory proposed by Leech (1981) and Hook in Widarso (1989). The researcher took 11 articles from Tempo English magazine April 14, 2020 edition collected by using purposive sampling. The findings data showed there are 27 data of connotative meaning of coronavirus impact expressions in Tempo English magazine April 14, 2020. It consists of 15 data of negative connotative meaning and 12 data of positive connotative meaning.

\section{The negative connotative meaning of coronavirus impact expressions in Tempo English April 14, 2020 edition}

There are five data found in this edition:

\section{Data 1}

After a month of the coronavirus disease 2019, or

Covid-19, pandemic bringing everything to a halt,

Indonesia must now face a second problem: a sharp

increase in unemployment.

(Unemployment Crisis, pr. 1, line 1-4)

Leech $(1981$, p. 13) states that talking about connotation is talking about the real world. The connotative is about experience of one that associates with an expression when one uses or hears it. Besides, connotations tend to change from time to time and from society to society. The word coronavirus in the sentence above shows that the coronavirus has a connotative meaning as something that threatens and harms the Indonesian society in the labor sector. In other words, coronavirus is associated as a threat.

Hook in Widarso (1989, p. 71) states that connotative meaning there are positive and negative. Hook also called positive connotative meaning as purr words 
while negative connotative meaning as snarl words. According to Hayakawa in Leech (1981, p. 41) states that snarl words are words in connotation in order to give forceful expression to his own hostility. Terms for extreme political views, such as communist or fascist. The opposite category of purr words has already been illustrated in the word democratic, other potential political purr words are freedom, human rights, patriotic, fatherland, and equality. In summary, snarl words (negative connotation) are terms that make people react negatively, while purr words (positive connotation) are terms that make people feel comfortable with the subject being addressed. Based on the explanation, the word coronavirus has a negative connotative meaning. It is caused the word coronavirus is a word in unfavorable connotation in order to give an expression as something that is threatening.

Data 2

So far, the government has not implemented the right policies to support the newly unemployment. When millions of people lost their job, President Joko Widodo responded by accelerating the rollout of the pre-employment card-a program for job seekers that had been promised during last year's presidential election campaign. This Rp20 trillion-program is not appropriate for this problem because part of it is in the form of paying training costs.

Cardholders can use the deposit on their cards to pay the training that they choose.

(Unemployment Crisis, pr. 5, line 1-9)

The expression accelerating the rollout of the pre-employment card in the sentence above has a connotative meaning. As Kreidler $(1998$, p. 44) said that meaning is more than denotation. People not only write to describe things, events, and characteristics but also to express various kinds of meaning attitudes which are called connotation. The pre-employment card is a program for job seekers that Joko Widodo promised during the presidential election campaign (Sulistyowati, et al., 2020), it is a good program for the labor sector. On the other hand, the expression accelerating the rollout of the pre-employment card in the sentence above expresses a kind of meaning attitude that the pre-employment card is not the right program for tackling unemployment.

As Hook in Widarso (1989, p. 71) states that connotative meaning there are positive and negative connotative. Hook also called positive connotative meaning as purr words while negative connotative meaning as snarl words. Snarl is when somebody or something (such as dogs, etc.) shows the teeth and makes a deep angry noise in the throat or speaks in an angry or bad-tempered way (Hornby, 2010, p. 1408). In other words, snarl word (negative connotation) is a term that makes somebody or something react negatively. In line with the concept, the expression accelerating the rollout of the pre-employment card in the sentence above make hearers or readers react negatively because the expression refers to an inappropriate program in overcoming unemployment due to the impact of coronavirus. Therefore, it has the negative connotative meaning.

\section{Data 3}

The textile industry, which has

been competing with imported products

in the past year, for instance, has not fared

better. Textile companies' cash flow is

suffering due to reduced, delayed and 
cancelled orders, not to mention the declining output of factories as the side of

social distancing regulations.

(The Wave of Unemployment, pr. 8, line 5-12)

The expression social distancing regulations in the sentence above has a connotative meaning. According to Leech (1981, p. 13), denotative meaning is stable while connotative meanings are relatively unstable, it considers several things, whether the culture, the historical period, the surrounding environment, or the experience of the individual. Thus, for a society the connotative meaning is considered a positive value but probably for some of the other societies the connotative meaning is considered a negative value or perhaps neutral. The expression social distancing regulations is actually a solution to avoid spread of coronavirus. But in certain situations, the use of the expression social distancing regulations is associated with bad impact. From the explanation, the connotative meaning of social distancing regulations in the sentence above does not explain the practice of physical restrictions with other people in order to prevent the spread of disease but it shows that social distancing regulations are interpreted as a threat to the sustainability of the textile industry and cause a decrease in production demand.

Hook in Widarso $(1989$, p. 71$)$ states that connotative meaning there are positive and negative connotative. Between positive connotative meaning and negative connotative meaning is neutral words, some of which are jargon. Hook also called positive connotative meaning as purr words while negative connotative meaning as snarl words. Snarl is when somebody or something (such as dogs, etc.) shows the teeth and makes a deep angry noise in the throat or speaks in an angry or bad-tempered way (Hornby, 2010, p. 1408). In other words, snarl word (negative connotation) is a term that makes somebody or something react negatively. In line with the concept, the expression social distancing regulations in the sentence above has the negative connotative meaning. It is caused the expression social distancing regulations is a expression in unfavorable connotation in order to give an expression of regulation that is detrimental to the textile industry.

Data 4

According to East

Java Governor Khofifah Indar Parawansa,

151 companies in her region have sent home

and fired 18,000 workers because of the

corona pandemic.

(The Wave of Unemployment, pr. 11, line 4-8)

The expression sent home and fired in the sentence above has a connotative meaning. Leech $(1981$, p. 12) states that connotative meaning is the meaning that has a communicative value of what it refers to and it has the meaning that above denotative meaning. There are many factors that cause people to be laid off. But in certain situations, a pandemic can cause people to be laid off. When a pandemic occurs, then the wheels of industry have stopped turning. Therefore, in connotative meaning, the expression sent home and fired in the sentence above means that new unemployment is one of the impacts of corona pandemic. As Leech (1981, p. 13) said that denotative meaning is stable while connotative meanings are relatively unstable, it considers several things, whether the culture, the historical period, the surrounding environment, or the experience of the individual (Leech, 1981, p. 13). 
Based on the explanation above, the expression sent home and fired in the sentence above has a negative connotative meaning. It is caused the expression sent home and fired is a negative impact of corona pandemic that employees did not expect, then sent home and fired make employees react negatively because it threatens to increase the number of poverty.

\section{Data 5}

Mass firing has been a new specter

haunting the world besides Covid-19 itself.

In mid-March, the International Labor Organization

(ILO) urged the governments of all

countries to boost their social safety net

programs and intervene into businesses

through policies to overcome the potential

spike in unemployment.

(The Wave of Unemployment, pr. 14, line 1-8)

The expression haunting the world has a connotative meaning. It is caused the expression haunting the world has above purely conceptual meaning. Leech (1981, p. 12) states that connotative meaning is the meaning that has a communicative value of what it refers to and it has the meaning that above conceptual meaning. Conceptually, haunting means sad or frightening in a way that cannot be forgotten, an expression showing that somebody is very worried (Hornby, 2010 , p. 688). Then the world means the earth with all its countries, people and natural features (Hornby, 2010, p. 1716). However, in connotative meaning, the expression haunting the world in the sentence mass firing has been a new specter haunting the world besides Covid-19 itself means that covid-19 is not only a disease that threatens the safety of many people in the world but also becomes a major threat to mass layoffs.

Based on the explanation above, the expression haunting the world in the sentence mass firing has been a new specter haunting the world besides Covid-19 itself has a negative connotative meaning. Hook in Widarso $(1989$, p. 71) states that connotative meaning there are positive and negative. Between positive connotative meaning and negative connotative meaning is neutral words, some of which are jargon. Hook also called positive connotative meaning as purr words while negative connotative meaning as snarl words. According to Hayakawa in Leech (1981, p. 41) states that snarl words are words in unfavorable connotation in order to give forceful expression to his own hostility. Terms for extreme political views, such as communist or fascist. The opposite category of purr words has already been illustrated in the word democratic, other potential political purr words are freedom, human rights, patriotic, fatherland, and equality. In summary, snarl words (negative connotation) are terms that make people react negatively, while purr words (positive connotation) are terms that make people feel comfortable with the subject being addressed. Based on the explanation, the expression haunting the world has a negative connotative meaning. This is due to the unfavorable connotation in order to give an expression as something that is threatening and make people react negatively. 


\section{The negative connotative meaning of coronavirus impact expressions in Tempo English April 14, 2020 edition}

There are also five data found in this edition:

Data 1

In fact, the government has already responded

to the potential spike in unemployment

and poverty due to Covid-19

through changes in the country's finance

policy, which came into effect two weeks

ago. As much as Rp405.1 trillion has been

added to the budget allocated to mitigating

the corona pandemic.

(The Wave of Unemployment, pr. 17, line 1-8)

The expression already responded in the sentence above has a connotative meaning. This is because the meaning of already responded is more than conceptual meaning. Connotative meaning is the meaning that has a communicative value of what it refers to and it has the meaning that above conceptual meaning (Leech, 1981, p. 12). It means that connotative meaning is more than conceptual meaning and apart from its core meaning because the connotative meaning has a communicative value of what it refers to. Conceptually, already means before now or before a particular time in the past (Hornby, 2010, p. 40) while respond means to do something as a reaction to something that somebody has said or done (Hornby, 2010, p. 1258). However, the meaning will be different meaning if it is contrasted with connotative meaning. Further, Kreidler (1998, p. 44) states that people not only write to describe things, events, and characteristics but also to express various kinds of meaning attitudes which are called connotation. Thus, the expression already responded in the sentence above is not only describes a reaction to something but also refers to the government's responsibility and seriousness in dealing with the impact of coronavirus.

From the explanation above, the expression already responded has a positive connotative meaning. Hook in Widarso $(1989$, p. 71$)$ states that connotative meaning is divided into two types, they are positive and negative. The positive connotative meaning also known as purr words while negative connotative meaning as snarl words. According to Oxford dictionary, purr is when a cat purrs, it makes a low continuous sound in the throat especially when it is happy or comfortable. Besides, purr refers to speak in a low and gentle voice, for example to show happiness or satisfy (Hornby, 2010, p. 1193). In other words, purr words (positive connotation) is a term that makes somebody or something feel happy, satisfied, and comfortable. Based on the explanation and the theories above, the expression already responded in the sentence above is the positive connotative meaning. It is caused the expression refers to something comfortable.

\section{Data 2}

A video

was circulating, depicting Jokowi and his

motorcade distributing hundreds of packages

containing staples to people in Jalan

Padjajaran, Bogor, West Java, while on his

way to Jakarta from the Bogor palace. 
(The Wave of Unemployment, pr. 20, line 1-6)

The expression distributing hundreds of packages containing staples has a connotative meaning. According to Leech $(1981$, p. 12), connotative meaning is the meaning that has a communicative value of what it refers to and it has the meaning that above conceptual meaning. Therefore, the expression distributing hundreds of packages containing staples in the sentence above is not only describes about an event but also has an additional meaning component that is associated with the government's concern for society.

From the explanation above, the expression distributing hundreds of packages containing staples in the sentence above has a positive connotative meaning. It is caused the expression distributing hundreds of packages containing staples refers to the concern of the Joko Widodo administration to Indonesian society. Thus, the expression shows a good attitude as well as provides good value for hearers or readers. As stated by Finch $(2003$, p. 135) that when talking about connotative meaning is talking about the kinds of value and attitudes brought up by a word apart from its core meaning.

\section{Data 3}

Ari says his ministry has stopped

promoting tourism and relocated the budget

to help mitigating the impacts of the

coronavirus. According to Presidential

Regulation No. 54/2020 on changes in the posture

and details of the 2020 state budget,

the tourism ministry's budget is now at

Rp4.26 trillion, Rp207 billion less than

the initial allocation.

(Under Threat, pr. 14, line 1-9)

The expression stopped promoting tourism has a connotative meaning. This is because the expression has the meaning that above conceptual content. According to Leech $(1981$, p. 12), connotative meaning is the meaning that has a communicative value of what it refers to and it has the meaning that above conceptual meaning (Leech, 1981, p. 12). The use expression stopped promoting tourism refers to the government's decision to anticipate an increase in the number of positive cases of Covid-19. In addition, by stopping promotion, the government has more budget to help the society affected by corona in the economic sector.

The connotative meanings are relatively unstable, it considers several things, whether the culture, the historical period, the surrounding environment, or the experience of the individual (Leech, 1981, p. 13). Thus, for a society the connotative meaning is considered a positive value but probably for some of the other societies the connotative meaning is considered a negative value or perhaps neutral. The expression stopped promoting tourism is actually negative connotation. Tourism industry in Indonesia is an important component for the Indonesian economy and also source of foreign exchange. Thus, the closure of tourism is something that is not expected. However, in certain situations, the use of expression stopped promoting tourism is associated with preventing the spread of coronavirus as well as government policy in dealing with the impact of coronavirus on the economic sector.

Based on the explanation above, the expression stopped promoting tourism in the sentence above has a positive connotative meaning. Hook in Widarso (1989, 
p. 71) states that connotative meaning is divided into two types, they are positive and negative. The positive connotative meaning also known as purr words while negative connotative meaning as snarl words. According to Oxford dictionary, purr is when a cat purrs, it makes a low continuous sound in the throat especially when it is happy or comfortable. Besides, purr refers to speak in a low and gentle voice, for example to show happiness or satisfy (Hornby, 2010, p. 1193). In other words, purr words (positive connotation) is a term that makes somebody or something feel happy, satisfied, and comfortable. Based on the explanation and the theories above, stopped promoting tourism in the sentence above is pleasant connotation, it is the positive connotative meaning.

\section{Data 4}

Said Ari, several programs

have been implemented to reduce the

potential for job termination. He added that

the ministry is cooperating with various

hotel networks to facilitate rooms for 1,300

medical personnel. "The hope is that this

partnership can provide cash flow because

the requirement is that they may not fire

employees", he said.

(Under Threat, pr. 15, line 1-9)

The expression the ministry is cooperating with various hotel networks has a connotative meaning. As Leech $(1981$, p. 13) said that the connotative is about experience of one that associates with an expression when one uses or hears it. Besides, Kreidler (1998, p. 44) said that connotative meaning refers to personal aspects and emotional that the word arouses. It means that connotative meaning is more than conceptual meaning and apart from its core meaning. From the explanation and the theories above, it shows that the use expression the ministry is cooperating with various hotel networks is associated with win-win solution. It is caused when the ministry decided to establish partnerships with hotels, then the hotel can maintain their business as well as reduce the risk of layoffs. In addition, medical personnel also have room facilities when handling the coronavirus cases.

From the explanation above, the expression the ministry is cooperating with various hotel networks in the sentence above has a positive connotative meaning. This is because the expression refers to win-win solution, it is pleasant connotation. According to Hook in Widarso $(1989$, p. 71$)$, connotative meaning is divided into two types, they are positive and negative. Between positive connotative meaning and negative connotative meaning is neutral words, some of which are jargon. The positive connotative meaning also known as purr words while negative connotative meaning as snarl words. According to Oxford dictionary, purr is when a cat purrs, it makes a low continuous sound in the throat especially when it is happy or comfortable. Besides, purr refers to speak in a low and gentle voice, for example to show happiness or satisfy (Hornby, 2010, p. 1193). In other words, purr words (positive connotation) is a term that makes somebody or something feel happy, satisfied, and comfortable. Based on the explanation and the theories above, the use expression the ministry is cooperating with various hotel networks has the positive connotative meaning. 


\section{Data 5}

Said Ari, several programs

have been implemented to reduce the

potential for job termination. He added that

the ministry is cooperating with various

hotel networks to facilitate rooms for 1,300

medical personnel. "The hope is that this

partnership can provide cash flow because

the requirement is that they may not fire

employees", he said. Another partnership

with the same goal in mind is now being

developed with at least 2,500 fashion

businesses to make fabric face masks.

(Under Threat, pr. 15, line 1-12)

The expression make fabric face masks in the sentence above has a connotative meaning. This is because the expression not only describes about fashion businesses who make fabric face masks but also expresses an attitude. According to Kreidler (1998, p. 44), people not only write to describe things, events, and characteristics but also to express various kinds of meaning attitudes which are called connotation. Since the government announced that the coronavirus had entered Indonesia, there are so many sectors who have been impacted by the weakening of the economy due to the corona pandemic, including fashion business sector. From the explanation, it shows that fashion business that makes fabric face masks become a solution to reducing the potential for job termination as well as taking advantage of the face mask business opportunity when many customers need face masks during the pandemic. Thus, connotatively, the use expression make fabric face masks is associated with solutions and new opportunities.

For a society the connotative meaning is considered a positive value but probably for some of the other societies the connotative meaning is considered a negative value or perhaps neutral. As Widarso $(1989$, p. 69) said that sometimes a word generally has a positive connotation, at least neutral, but some are considered negative by certain groups. The expression make fabric face masks is actually a neutral connotation. However, in certain situations, the use of expression make fabric face masks is associated with solution to reducing the potential for job termination and also associated with taking advantage of the face mask business opportunity when many customers need face masks during the pandemic. Therefore, the expression make fabric face masks in the sentence above masks has a positive connotative meaning. This is because the expression make fabric face masks refers to a pleasant connotation.

\section{CONCLUSIONS}

The result of this research is that Tempo English magazine uses many connotative meaning of coronavirus impact expressions. There are 15 expressions as negative connotative meaning and 12 expressions as positive connotative meaning. Based on the discussions above, it shows that the use negative connotative meaning of coronavirus impact expressions in Tempo English magazine are associated with threats in economy sector and associated with inappropriate government policies in an effort to prevent the spread of covid-19 as well as the impact of pandemic in many sectors. Besides, the use positive connotative meaning of coronavirus impact 
expressions in Tempo English magazine are associated with solutions to avoid spread of Covid-19 as well as solutions to avoid the impact of pandemic, and associated with the government's responsibility and seriousness in dealing with preventing the spread of coronavirus as well as in dealing with the impact of coronavirus.

\section{REFERENCES}

Berg, B. L. (2001). Qualitative Research Methods for the Social Sciences. Boston: Allyn \& Bacon.

Bogdan, R. C., \& Biklen, S. K. (2006). Qualitative Research for Education: An Introduction to Theory and Methods (5th ed.). Boston, Massachusetts: Pearson.

Budd, R. W., Thorp, R. K., \& Donohew, L. (1967). Content Analysis of Communication. New York: Collier-Mac.

Chaer, A. (2009). Pengantar semantik Bahasa Indonesia. Jakarta: Rineka Cipta.

Creswell, J. W. (2014). Research Design: Qualitative, Quantitative, and Mixed Methods Approaches (4th ed.). Thousand Oaks: Sage Publications, Inc.

Finch, G. (2003). How to Study Linguistics: A Guide to Understanding Language (2nd ed.). New York: Palgrave Macmillan.

Hornby, A. S. (2010). Oxford Advanced Leaner's Dictionary: International Student's Edition. Oxford: Oxford University Press.

Kreidler, C. W. (1998). Introduction English Semantics. New York: Routledge.

Leech, G. (1981). Semantics Study of meaning (2nd ed.). London: Penguin Books.

Lyons, J. (1995). Introduction to Theoretical Linguistics. London: Cambridge University Press.

Pateda, M. (2001). Semantik Leksikal. Jakarta: Rineka Cipta.

Riemer, N. (2010). Introduction Semantics. New York: Cambridge University Press.

Saeed, J. I. (2016). Semantics (4th ed.). Chichester: Wiley Blackwell.

Schreier, M. (2012). Qualitative Content Analysis in Practice. Thousand Oaks: Sage Publication.

Shannon, S. E., \& Hsieh, H.-F. (2005). Three Approaches to Qualitative Content Analysis. Qualittaive Health Research, XV(9), 1277-1288.

Steele, J. (2005). War within: The Story of Tempo, an Independent Magazine in Soeharto's Indonesia . Jakarta: Equinox Publishing.

Widarso, W. (2000). Bahasa Inggris: Dialek, Ragam, Jargon, Slang, Blends, Clipped Words. Yogyakarta: Kanisius.

Zhang, Y., \& Wildemuth, B. M. (2005). Qualitative Analysis of Content. Human Brain Mapping, 30(7), 2197-2206. 